This item was submitted to Loughborough's Research Repository by the author.

Items in Figshare are protected by copyright, with all rights reserved, unless otherwise indicated.

\title{
Regional centrality and tax competition for FDI
}

PLEASE CITE THE PUBLISHED VERSION

http://dx.doi.org/10.1016/j.regsciurbeco.2014.08.006

\section{PUBLISHER}

(C) Elsevier

\section{VERSION}

AM (Accepted Manuscript)

\section{PUBLISHER STATEMENT}

This work is made available according to the conditions of the Creative Commons Attribution-NonCommercialNoDerivatives 4.0 International (CC BY-NC-ND 4.0) licence. Full details of this licence are available at: https://creativecommons.org/licenses/by-nc-nd/4.0/

\section{LICENCE}

CC BY-NC-ND 4.0

\section{REPOSITORY RECORD}

Darby, Julia, Benjamin E. Ferrett, and lan Wooton. 2019. "Regional Centrality and Tax Competition for FDI". figshare. https://hdl.handle.net/2134/23369. 


\section{Accepted Manuscript}

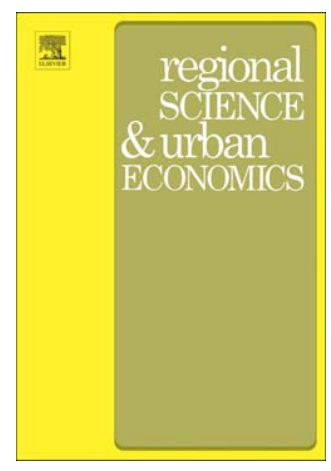

Regional Centrality and Tax Competition for FDI

Julia Darby, Ben Ferrett, Ian Wooton

PII: $\quad$ S0166-0462(14)00088-X

DOI: $\quad$ doi: $10.1016 /$ j.regsciurbeco.2014.08.006

Reference: $\quad$ REGEC 3082

To appear in: $\quad$ Regional Science and Urban Economics

Received date: $\quad 1$ April 2014

Revised date: $\quad 30$ July 2014

Accepted date: 14 August 2014

Please cite this article as: Darby, Julia, Ferrett, Ben, Wooton, Ian, Regional Centrality and Tax Competition for FDI, Regional Science and Urban Economics (2014), doi: 10.1016/j.regsciurbeco.2014.08.006

This is a PDF file of an unedited manuscript that has been accepted for publication. As a service to our customers we are providing this early version of the manuscript. The manuscript will undergo copyediting, typesetting, and review of the resulting proof before it is published in its final form. Please note that during the production process errors may be discovered which could affect the content, and all legal disclaimers that apply to the journal pertain. 


\title{
Regional Centrality and Tax Competition for FDI
}

\author{
Julia Darby \\ University of Strathclyde \\ Ben Ferrett \\ Loughborough University \\ Ian Wooton \\ University of Strathclyde, CEPR and CESifo
}

22 AuguST 2014

\begin{abstract}
We examine a trade model where three countries compete for an exogenous number of firms. In our hub-and-spoke framework, one country is the hub through which all trade with and between spokes takes place. We establish the distribution of industrial activity in the absence of taxes and compare it to the equilibrium when countries compete to attract firms. Even when all countries are the same size, the centrality of the hub sets it apart. We determine how this trading pattern matters, comparing it to a structure with direct trade between all countries. The implications of international tax competition are also examined.
\end{abstract}

Keywords: corporate taxes, devolution, trade costs, hub and spoke

JEL Classification: F15, F23, H25, H73

\footnotetext{
We are grateful for comments and suggestions from participants in seminars at the universities of Duisburg-Essen, Loughborough, Oxford (Centre for Business Taxation), Tübingen, wiiw Vienna and from presentations at the Midwest International Trade Meeting at Michigan State University, a Workshop on Asia and World Trade at Seoul National University and CESifo Global Economy conference.
} 


\section{Introduction}

This paper examines international tax competition to attract foreign direct investment (FDI) in a regional model with trade costs between countries. Our innovation lies in the geography of the region. If there are only two countries in a region, international trade would take place across the common frontier of the countries. ${ }^{1}$ If there are three countries or more, past work (e.g., Haufler and Wooton, 2006) has assumed a "triangular" geography, where each country pair shares a frontier and trade between these two nations takes place across this line. But this excludes the possibility that, in regions composed of three or more countries, the most direct or cheapest route for goods traded between two nations might be through the territory of a third. Thus a 3-country region may be composed of one hub country and two spoke nations, where each spoke accesses the market of the other spoke by shipping its products through the hub. Clearly, this implies an asymmetry in international transport costs, apparently favouring the centrally placed hub. We wish to investigate how the adoption of this hub-and-spoke geography affects the established results for the outcome of tax competition for FDI.

This paper was motivated by the debate regarding increased autonomy for the devolved administrations in the UK. There are strong political pressures to devolve corporate tax-setting powers to the Scotland, Wales and Northern Ireland. Given the geography of the $\mathrm{UK}$, this raises questions as to how such fiscal independence might affect the level and geographic distribution of economic activity and impact on the welfare of citizens. ${ }^{2}$ Thus the hub-and-spoke geographic structure we have adopted is an attempt to reflect the economic

\footnotetext{
${ }^{1}$ Of course, the countries may be islands in which case a body of water separates them but there is still a common frontier to be crossed at some cost.

2 The Scottish Government argues "that a unified UK rate of corporate tax is neither desirable nor economically efficient. (...) Given the competitive advantages of London relative to other parts of the UK (such as London's position as one of the largest financial centres in the world, and its transport links with major cities worldwide etc.) there is clear evidence that London (and indeed the South East of England) already has an in-built competitive advantage over not only Scotland but also other parts of the UK. Scotland needs the lever of corporate tax to consider a wider array of options than is currently the case to help address this imbalance." Scottish Government (2011), p34.
} 
and spatial relationships within the UK and between it and the wider European market. However, despite the genesis of our modelling endeavour, the analysis is readily applicable to many situations where trade costs between countries are not symmetric. For example, North America is an obvious case of hub-and-spoke geography. The USA is the hub nation that both trades with each of the two spokes of Canada and Mexico, and it is also the conduit for trade between the spokes.

At the centre of our analysis are the attempts by governments to attract inward FDI. FDI results in increased local production and employment within the industry concerned, and we assume that this local production of the good yields higher social benefits than imports. This reflects what seems to be a widely-held government view. There are many possible reasons why, independently of capital income and tax/subsidy payments, host countries may favour local production. In the analysis in this paper, trade between any two countries is costly while production costs are the same in all countries. As a result, the market price is lower (and consumer surplus higher) when goods are locally produced as compared to being imported from another country in the region. Benevolent governments will recognise this and seek to attract FDI. ${ }^{3}$

Our starting point is Haufler and Wooton's (2010) model of international competition to attract the FDI of firms in an oligopolistic industry. ${ }^{4}$ In 2-country models of this type, the existence of international trade costs confers an advantage on the larger country in the competition for firms, as a large country offers a bigger domestic market that can be served without trade costs. Thus size matters. We increase the number of countries to three and allow for different configurations of the population across the region.

\footnotetext{
${ }^{3}$ Beyond this motivation, there may be labour market benefits from inward FDI. MNEs may offer wage premia above workers' outside options, a polar case of which occurs when inward FDI relieves involuntary unemployment (Haaparanta, 1996 and Bjorvatn and Eckel, 2006). Alternatively, inward FDI may be associated with localised technological spillovers to indigenous firms (Fumagalli, 2003 and Olsen and Osmundsen, 2003).

${ }^{4}$ Haufler and Wooton (1999) initially consider competition for a single firm. This was extended to two firms by Ferrett and Wooton (2010) and to an oligopolistic industry by Haufler and Wooton (2010).
} 
Crucially, what further distinguishes the current analysis is our assumption that one of the three countries occupies a central point geographically, such that all traded goods must pass across its frontiers at least once. This hub country can trade directly with each of the other two nations but, in contrast, firms located in either spoke country can only access the consumers in the other peripheral spoke country by shipping their goods through the hub. ${ }^{5}$ As shipping goods across national frontiers is assumed to be costly, firms located in the spokes are at a disadvantage in serving each other's markets, as compared to those firms located in the hub. Consequently, we are adding centrality, in addition to size, as a determinant of national geographic advantage within the region.

There are alternative interpretations or applications of the model that might shine some light on current policy questions. One is that the model represents a single country whose geography means that trade between some provinces is more expensive than others. Thus it could represent industrial activity in a country such as the UK, where trade between Scotland and Wales must take place through much-larger England. The model could then be used to analyse the potential for the two relatively disadvantaged provinces to use devolved corporate tax-setting powers to offset their geographic disadvantages. Another modelling possibility would be to consider a two-country setting where one of the countries is "bicentric", having two centres of economic activity that are physically distant from one another. This might characterise trade within the UK (between Scotland and England) and between the UK and the wider European market. The implication of this is that movement of goods between nodes within the bicentric country will also be costly and the location of firms within such a country, as well as their number, will play a role. If one of this country's nodes (England) is closer to the foreign market, this will be the hub through which all exports and

\footnotetext{
5 Haufler and Wooton (2006) have a 3-country, single-firm model of tax competition in a regional setting where the focus is on the implications of tax harmonisation between two of the nations. In our companion paper, Darby, Ferrett and Wooton (2012), we examine the outcome of tax competition between $m$ heterogeneous countries but without a hub-and-spoke trading pattern.
} 
imports pass. The other node (Scotland) is therefore geographically disadvantaged, both by its smaller size and by its peripheral location, in its chances of attracting the FDI of firms aiming to service consumers across the entire region. This has the potential to create a tension between citizens resident in one node and those in the other, and may lead to calls for different rates of corporate taxation of firms in order to offset the locational disadvantages of one centre relative to the other. ${ }^{6}$

Our analysis develops as follows. In section 2 we present the basic hub-and-spoke model and examine the geographic distribution of firms in the absence of any corporate tax competition. We then, in section 3, consider the non-cooperative tax equilibrium in the region resulting from national attempts to attract additional firms. Section 4 examines the importance of the trading structure by comparing it to one in which all three countries trade directly with one another. In Section 5, we compare the outcome of tax competition with that where a single regional tax authority is empowered to set the corporate taxes for all three countries. Finally, section 6 concludes.

\section{The baseline model}

We consider an economic region whose countries compete to attract a fixed number of firms. These firms produce a homogeneous good, labelled $x$, in an oligopolistic industry. A second good, the numeraire commodity $z$, is produced under conditions of perfect competition. The numeraire industry, which uses labour as its only input, is freely traded, resulting in the international equalisation of the wage in that industry as $w$. Trade costs play an important role in the model. It is assumed that $z$ is freely traded while $x$ is subject to trade costs. ${ }^{7}$

\footnotetext{
${ }^{6}$ It is clear that many of Scotland's key exports do pass through England to access European markets. For example, Scottish Government (2009) reports that oil exports "are piped to England (or via England to Continental Europe)" (p46) while "much of the whisky destined for European consumption is transported by road to cross the Channel at Dover" (p52), and in the case of fish "significant road freight movement (...) is to the south of England before being transported to mainland Europe for distribution around the World"(p55).

7 Our assumption that the numeraire good is freely traded is common to much of the literature in "new" economic geography as it allows the focus to be on location and production of a particular, imperfectly
} 
The region is composed of 3 countries, a hub country $H$, and two spoke countries $S_{1}$ and $S_{2}$. The internationally immobile population is divided into households, each of which supplies labour effort and consumes both of the goods produced in the region. Every household in the region supplies a single unit of labour, and we normalise the total number of households across the region to 1 . We allow the countries to differ in size such that there are $n$ households in the hub. In order to facilitate the examination of the relative importance of being at the core of the region as opposed to being on the periphery, it will be useful to introduce symmetry across the spoke countries. Thus, we suppose that the two spokes are identical in size, each having a population of $(1-n) / 2$.

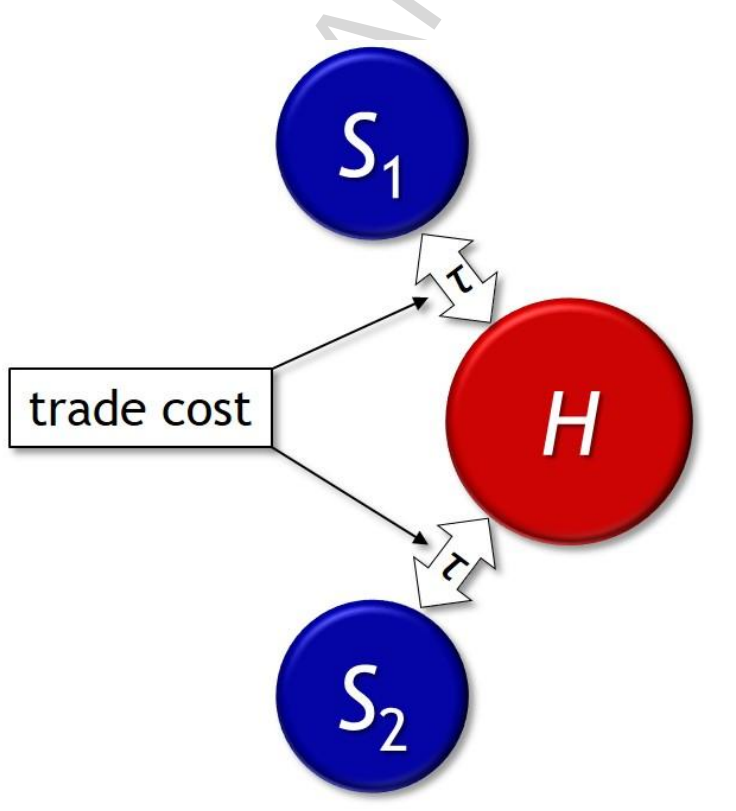

Figure 1. Geography of the symmetric region

The cost of shipping a unit of good $x$ between the hub and either spoke is equal to $\tau$. There is no direct trade route between the two spokes (or it is prohibitively expensive). Hence all shipments of good $x$ between the two spokes must pass through the hub and, consequently, relative prices. 
face a higher cost for transhipment of $2 \tau^{8}$ This regional trading situation is illustrated in Figure 1.9

\subsection{Consumers}

Consumers in all countries are assumed to have identical preferences for the goods, given by

$$
u_{i}=\alpha x_{i}-\frac{\beta}{2} x_{i}^{2}+z_{i}
$$

where $i \in\left\{H, S_{1}, S_{2}\right\}$. The residents of the countries earn only wage income, while profit income accrues to capital owners who reside outside of the region. Moreover, corporate tax revenue, denoted by $T_{i}$, is redistributed as income in a lump-sum fashion equally to the households in the respective country. The budget constraint for a representative consumer in country $i$ is then

$$
w+\frac{T_{i}}{n_{i}}=z_{i}+p_{i} x_{i}
$$

where $p_{i}$ is the relative price of $\operatorname{good} x$ in country $i$. Utility maximisation leads to inverse-demand curves $\alpha-\beta x_{i}$. Aggregating the demand for good $x$ over all consumers, yields market demand curves, denoted $X_{i}$, where

$$
X_{i}=\frac{n_{i}\left(\alpha-p_{i}\right)}{\beta}
$$

\subsection{The oligopolistic industry}

There are $k$ firms in the $x$ industry, all of which are based outside the region. ${ }^{10}$ Each of these firms possesses one unit of "knowledge capital" (such as a license or patent) that can be profitably employed in this imperfectly competitive industry. This factor is indispensable for the production of good $x$ but is limited in availability such that, at most, $k$ firms can engage in

\footnotetext{
${ }^{8}$ To keep the analysis relatively simple, we have assumed that there are no economies from long-distance shipping and that the cost of trade between the two spokes is the sum of the costs of each hub-to-spoke trade.

${ }^{9}$ In our working paper, Darby, Ferrett and Wooton (2013), we consider hub-and-spoke trade with less symmetry in the model.

${ }^{10}$ Examination of the impact of having some indigenous firms in the industry is left to future research.
} 
production. In addition, each firm faces fixed and identical costs of setting up a production facility in any country. These costs are assumed to be sufficiently large to ensure that each firm will set up, at most, one production plant in the region. Thus each firm will serve the entire regional market from a single country in the region. Firms are assumed to be identical except with respect to the location of their production facilities. Where it locates matters to a firm both because of the size of its local market and the trade costs associated with its exports to consumers in foreign markets. ${ }^{11}$

Labour is the only variable input in good $x$ production. Each unit of good $x$ requires the efforts of $\gamma$ workers, where $\gamma$ is chosen so that production of $x$ does not exhaust each country's labour supply. Given this, the marginal cost of production can be defined as $\omega \equiv \gamma w .^{12}$ The cost of exporting each unit of output, as detailed above, raises the marginal cost of serving a firm's foreign markets relative to supplying domestic consumers. We are assuming that all of the trade costs are "real", taking the form of, say, transport costs or administrative barriers to the free movement of goods between countries; and also that all of the trade costs are non-prohibitive, so that every firm serves every product market. There are no (endogenously determined) tariffs between the countries, as we assume that the region is a free-trade-area.

Firms are assumed to behave as Cournot competitors and are able to segment their markets, choosing the quantities to sell on each market independently. ${ }^{13}$ The total operating profit of a firm based in each production location is therefore

\footnotetext{
11 The fixed cost associated with each production plant means that there are increasing returns to scale in production and average cost could be reduced by rationalising production with fewer plants. However, firms are assumed to want to protect their knowledge capital from being emulated by competitors and consequently choose to operate independent production facilities.

12 Since the wage $w$ is equalised across the countries, it does not enter the location decision of firms in our model. Thus the firms' choice of location is not driven by labour costs.

13 In equilibrium, firms will receive a lower producer price for their exports than for goods destined for the domestic market. The trade structure is simply a generalisation of the "reciprocal dumping" model of Brander and Krugman (1983).
} 


$$
\begin{aligned}
& \pi_{S}=\left(p_{S}-\omega\right) x_{S}+\left\lfloor p_{H}-(\omega+\tau)\right\rfloor x_{H S}+\left\lfloor p_{S}-(\omega+2 \tau)\right\rfloor x_{S S}, \\
& \pi_{H}=\left(p_{H}-\omega\right) x_{H}+2\left[p_{S}-(\omega+\tau)\right] x_{S H},
\end{aligned}
$$

where $\pi_{i}$ and $x_{i}$ are the pre-tax profits and home sales, respectively, of a firm based in country $i$ and $x_{j i}$ represents exports to country $j$ by a firm based in country $i$. A firm is at a cost disadvantage in an export market as the marginal cost of exports is higher than that for domestic sales. Consequently we anticipate that an exporter will sell less in a market than its local rival.

Suppose that of the $k$ firms selling in country $i, k_{H}$ firms have their production facilities in the hub, while the remaining $\left(k_{S} \equiv k-k_{H}\right)$ firms serve the market from one of the two spoke nations (each hosting half of this number). ${ }^{14}$ Maximising (4), taking into account demand (3), and solving yields the total sales and price of good $x$ in each location:

$$
\begin{array}{ll}
X_{S}=\frac{(1-n)}{2} \frac{(\alpha-\omega-\tau) k}{\beta(k+1)}, & p_{S}=\frac{\alpha+(\omega+\tau) k}{k+1} \\
X_{H}=n \frac{(\alpha-\omega-\tau) k+\tau k_{H}}{\beta(k+1)}, & p_{H}=\frac{\alpha+(\omega+\tau) k-\tau k_{H}}{k+1} .
\end{array}
$$

In this symmetrical setting, the consumer price in the spokes is increasing in the trade cost and declining in the total number of firms operating in the region. This is also true of the price in the hub where, in addition, price is declining in the number of firms located in the hub, as a result of increasing local competition. Thus, as long as the hub attracts some firms, the price in the hub will be less than that in the spokes. Similarly, production per household of a firm in a spoke will be less than that of a firm in the more-competitive hub. Total output of the countries will further depend upon the number of households in each location.

Substituting the prices and quantities (5) into (4) yields the pre-tax profits of firms as a function of the location of their production facilities:

\footnotetext{
${ }^{14}$ We assume that $k$ is sufficiently large that we can treat the numbers of firms locating in each country as continuous variables. Ferrett and Wooton (2010) look at $k=2$, where the discrete nature of the FDI is central to the analysis.
} 


$$
\begin{aligned}
& \pi_{S}=\frac{(\mathrm{A}-\tau)^{2}+\tau^{2}(1-n)(k+1)^{2}+\tau n k_{H}\left[2(\mathrm{~A}-\tau)-\tau k_{H}\right]}{\beta(k+1)^{2}}, \\
& \pi_{H}=\frac{(\mathrm{A}-\tau)^{2}+\tau n\left(k-k_{H}+1\right)\left[2 \mathrm{~A}+\tau\left(k-k_{H}-1\right)\right]}{\beta(k+1)^{2}}
\end{aligned}
$$

where $\mathrm{A} \equiv \alpha-\omega$. Because trade costs offer some protection from foreign rivals, profits accruing to firms located in any country are driven down by higher concentrations of firms in that location.

We let $\Gamma$ denote the geographic advantage of the hub relative to either spoke. This is defined as the difference between the total variable profits of a firm located in the hub and those of a firm producing in a spoke. That is, $\Gamma \equiv \pi_{H}-\pi_{S}$.

\subsection{Location in the absence of tax competition}

Suppose, initially, that firms face no corporate taxes on their earnings or that all countries impose the same tax on firms. In either situation, the equilibrium location of firms will be characterised by the pre-tax profits of all firms in the region being equalised, that is $\pi_{H}=\pi_{S}$. Equating the terms in (6) and solving, reveals the "natural geography" of the region, the allocation of industry that is consistent with equal pre-tax profits for all $k$ firms. Thus $k_{i}^{*}$ is the equilibrium number of firms that locate in country $i$ in the absence of fiscal inducements, where:

$$
\begin{aligned}
& k_{S}^{*}=\frac{k+1}{4 n}-\frac{\mathrm{A}}{2 \tau}, \\
& k_{H}^{*}=\frac{\mathrm{A}}{\tau}-\frac{1-k(2 n-1)}{2 n} .
\end{aligned}
$$

We can use (7) to investigate the relationship between trade costs and the sizes of countries in determining the degree to which industry agglomerates in particular countries. We can define agglomeration as the ratio of firms in a country relative to national population. Thus, let $\lambda_{i} \equiv k_{i}{ }^{*} / n_{i}$ be the number of firms per household in country $i$ in the absence of tax 
competition. The hub always has the advantage of centrality, in that its aggregate costs of serving its foreign markets are always less than those of the spoke countries, as the hub transports its goods directly to consumers in each spoke whereas the spokes must send all of their exports through the hub. This aspect of geographic advantage can be enhanced, or offset, by the distribution of the region's population between hub and spokes. We illustrate this in Figure 2, where we redistribute the population from the spokes to the hub (raising $n$ and lowering $n_{S}$ ) as we move rightwards. There is a critical level of trade cost that is necessary to ensure that any firms choose to locate in the spokes. Thus $k_{S}^{*}>0$ only if $\tau>2 \mathrm{~A} n /(k+1)$. Below this, the firms will co-locate in the hub and service all markets from there. Similarly, the hub will only attract firms if trade costs are sufficiently low. Thus $k_{H}^{*}>0$ only if $\left.\tau<2 \mathrm{~A} n \Lambda 1-k(2 n-1)\right]$.

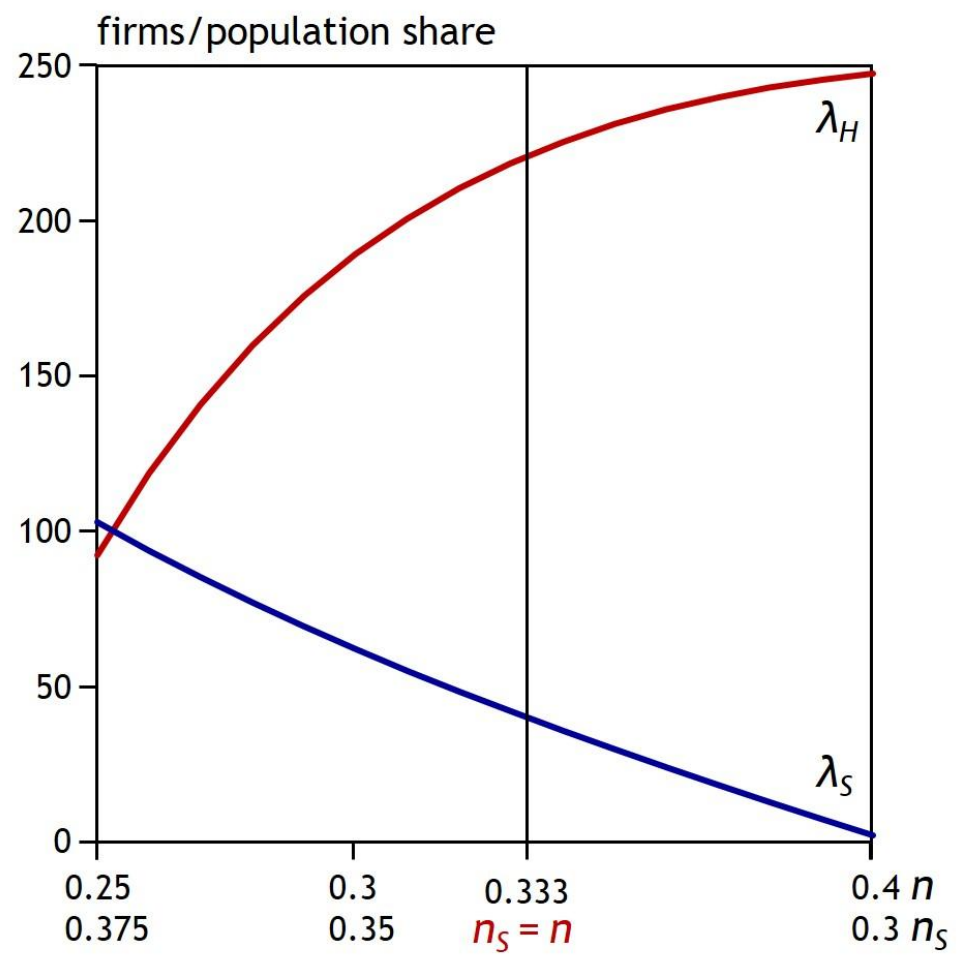

Figure 2. Natural geography and agglomeration of industry 
The benefit of centrality is clearly shown in Figure 2 along the vertical line at $n=1 / 3$, which corresponds to each country having the same number of households. ${ }^{15}$ In this case, the number of firms per household in the hub is substantially greater than that in each of the two spokes. For the hub, country size reinforces centrality to the right of this vertical line where $n$ rises at the expense of the population of the spokes. To the left of the vertical line, the spokes are allocated greater shares of the region's population than the hub, and diminishing size increasingly offsets centrality until the agglomeration is reversed and the spokes attract proportionately more of the industry.

We now consider the role of trade costs in the natural geography of the region. In Figure 3 each country is the same size $(n=1 / 3)$ but the trade cost is varied. Once again, we focus on the agglomeration of industry by reporting the number of firms per household in each country. When the trade cost is low, the hub's centrality results in its attracting much more industry than either spoke, as the hub's easy access to the local and its export markets offsets the strong competition amongst firms arising from their co-location in the hub. However, as the trade cost between the hub and spokes increases, it becomes increasingly expensive for firms in the hub to sell to consumers in the spokes while those firms that are located in the spokes benefit from the increased market power associated with their greater isolation from the hub. ${ }^{16}$

\footnotetext{
15 The parameters for this and subsequent numerical simulations are: $k=100, \alpha=26, \beta=1, \omega=1, \tau=0.2$.

16 If $\tau=0$, access to domestic and foreign markets is the same and, consequently, firm location is undefined. See Haufler and Wooton (2010) for a discussion of the relationship between declining trade costs and increasing agglomeration of industry.
} 


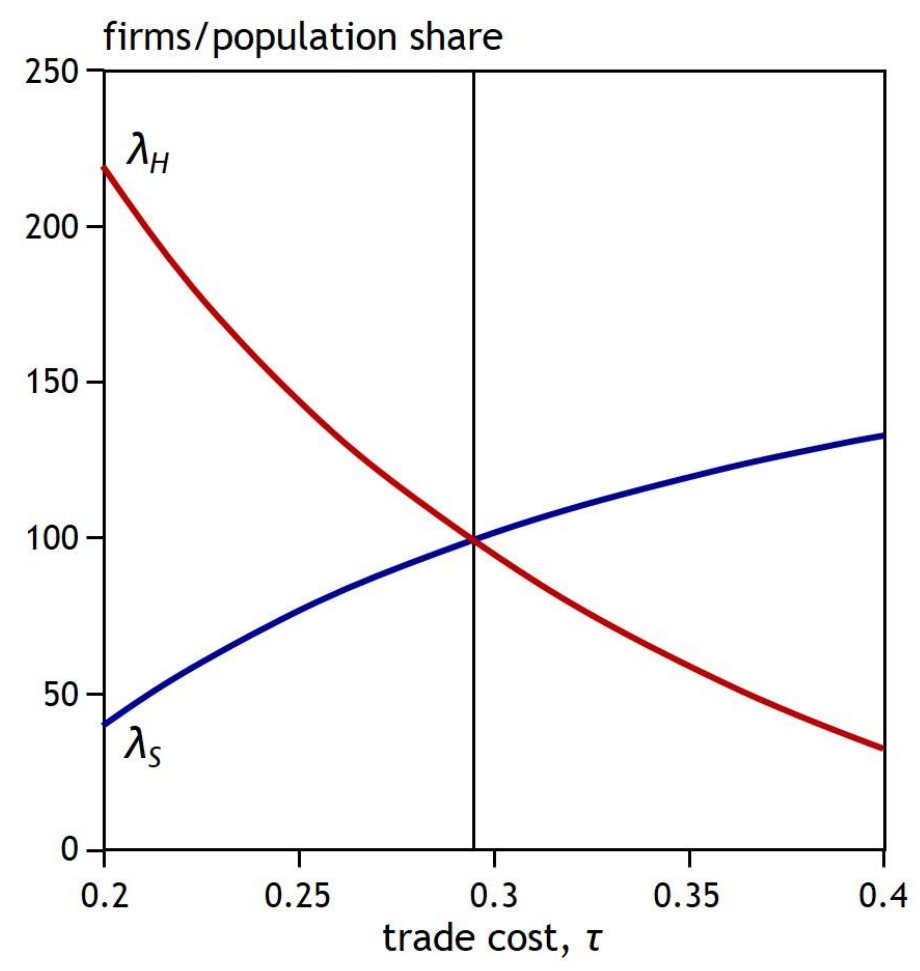

Figure 3. Natural geography and trade costs

We can use the natural geography of industrial production to determine the level of economic activity in the hub and the spokes. Substituting the equilibrium allocations of industry (7) into (5) gives us the equilibrium output and prices in the hub and the spokes in the absence of tax competition:

$$
\begin{array}{ll}
X_{S}=\frac{(1-n)(\mathrm{A}-\tau) k}{2 \beta(k+1)}, & p_{S}=\omega+\tau+\frac{\mathrm{A}-\tau}{k+1} ; \\
X_{H}=\frac{2 n \mathrm{~A}-\tau}{2 \beta}, & p_{H}=\omega+\frac{\tau}{2 n} .
\end{array}
$$

We see from (8) that trade costs impact on both the price in each national market and the quantity that is sold there. ${ }^{17}$

\footnotetext{
17 In Darby, Ferrett and Wooton (2013), we investigate the effects of changes in trade cost of one spoke with the hub while keeping the other spoke's direct trade cost unchanged.
} 


\section{Governments}

Each national government is assumed to have as its goal the maximisation of the welfare of its households, where welfare is the sum of the consumer surplus, tax revenue, and wage income. Profits do not appear in our welfare expression because we are assuming that all profits from the activities of the imperfectly competitive firms are repatriated to their foreign owners.

$$
W_{i} \equiv S_{i}+T_{i}+n_{i} w
$$

$S_{i}$ is country $i$ 's total consumer surplus in the market for the imperfectly competitive good, where

$$
\begin{aligned}
& S_{S}=\frac{(1-n)[(\mathrm{A}-\tau) k]^{2}}{4 \beta(k+1)^{2}}, \\
& S_{H}=\frac{n\left(\mathrm{~A} k-2 \tau k_{S}\right)^{2}}{2 \beta(k+1)^{2}},
\end{aligned}
$$

given the symmetry in the model. Consumer surplus in each country is rising in the total number of firms in the industry, $k$, as this intensifies competition and reduces producer prices in all countries. Higher trade costs reduce consumer surplus as they reduce international competition. In addition, the greater the number of firms located in other countries the lower the consumer surplus, as consumer prices are lower when more firms produce locally. This gives each nation an incentive to attract firms to its home jurisdiction.

$T_{i}$ is the total corporate tax revenue collected by country $i$,

$$
T_{i}=t_{i} k_{i}
$$

where $i \in\left\{H, S_{1}, S_{2}\right\}$. We assume that profits are taxed at source by the host countries of the firms, with $t_{i}$ being the lump-sum tax imposed on each firm by country $i$. A higher tax will expand the budget set of the host nation's households, but will drive firms away to a lower tax regime. As the identical spoke countries will always choose to set the same tax as each 
other in equilibrium, our interest lies in $\Delta$, the difference between the tax set by the hub and that chosen by the spokes. Thus, let $\Delta \equiv t_{H}-t_{S}$ be the hub/spoke tax difference.

The third term of national welfare is assumed to be unchanging, as wage income remains the same regardless of where workers are employed. We assume that the jobs provided by the oligopolistic industry offer the same wage as that in the numeraire industry. While it would be possible to include some sort of wage premium for jobs in the footloose industry, this would create similar incentives for attracting firms as consumer surplus, so we do not pursue it in this paper.

\subsection{Corporate taxation}

Firms are concerned with their after-tax earnings. Thus, they must subtract from their pre-tax profits (6) the lump-sum tax of the country in which they are located. In deciding upon where to invest, firms will compare profits net of taxes and locate in the most profitable location. If all countries host a strictly positive number of firms, then the locational equilibrium for the industry is characterised by the difference between the pre-tax profits of producing in the hub as compared to production in either spoke being exactly offset by the difference in the taxes imposed in the two types of country:

$$
\Gamma-\Delta=0
$$

We can solve for the distribution of firms in the presence of taxes as deviations from the natural geography of the region (the allocation of industry in the absence of taxes). Let $k_{i t}$ be country $i$ 's equilibrium number of firms in the presence of taxes. From (6), (7) and (12), we find:

$$
\begin{aligned}
& k_{H t}=k_{H}^{*}-\frac{\beta(k+1) \Delta}{2 \tau^{2} n}, \\
& k_{S t}=k_{S}^{*}+\frac{\beta(k+1) \Delta}{4 \tau^{2} n},
\end{aligned}
$$


when both spokes levy the same corporate tax. It is immediately obvious that only differences in taxes, not the levels of taxes, matter for industrial location in the region. If all countries have set the same tax, firm numbers in each country are the same as in the absence of any corporate taxes.

When taxes differ between hub and spokes, we can see, from the second terms of the equations in (13), that the hub loses firms as a result of its imposing taxes higher than those set in the spokes. The impact is mitigated by the (square of the) trade cost between the spoke and the hub. It is clear from this that the countries may have incentives to deviate from the tax levels of their trading partners (and, indeed, respond to any changes in taxes made by the other countries) in order to influence the number of firms that they attract. The task is then to determine what the equilibrium taxes will be in such a strategic setting. We therefore turn to finding the Nash taxes.

\subsection{Equilibrium taxes}

Suppose that each of the countries now sets a corporate tax to maximise its welfare, conditional on the taxes set by the other countries in the region. The reaction functions for the countries are

$$
\begin{aligned}
t_{H}= & \frac{\tau\lfloor 2 n(\mathrm{~A}+2 \tau k)-\tau(2 k+1)\rfloor}{\beta(4 k+3)}+\frac{2 k+1}{(4 k+3)}\left(t_{S 1}+t_{S 2}\right), \\
t_{S i} & =\frac{4 \tau(1-n)\left\{2 \tau(k+1)^{2}-n[(4+5 k) \mathrm{A}-\tau k]\right\}}{\beta(k+1)[8(k+1)-n]}+\frac{8(1-n)(k+1)}{8(k+1)-n} t_{H}-\frac{4(k+1)-(8 k+7) n}{8(k+1)-n} t_{S j} .
\end{aligned}
$$

Solving (14) and imposing symmetry on the spokes, yields the Nash corporate taxes $t_{S N}$ and $t_{H N}$ for a spoke nation and the hub, respectively:

$$
\begin{aligned}
t_{S N}= & \Theta(1-n)\left[4 \tau(k+1)^{3}+\tau k n\left(8 k^{2}+20 k+11\right)-\mathrm{A} n\left(16 k^{2}+23 k+8\right)\right], \\
t_{H N}= & \Theta\left\{\tau(2 k+1)(k+1)^{2}+\tau k n\left[\left(12 k^{2}+26 k+13\right)-n(2 k+3)(4 k+3)\right]\right. \\
& \left.-\mathrm{A} n\left[\left(4 k^{2}+k-2\right)-k n(6 k+5)\right]\right\},
\end{aligned}
$$


where $\Theta \equiv \tau /\left\{\beta(k+1)^{2}[8 \mathrm{k}+7-4(k+1)]\right\}>0$.

The tax levels in the Nash equilibrium associated with different distributions of the region's population and for different trade costs $(\tau=0.2$ and $\tau=0.3)$ are illustrated in Figure 4. It is clear that the Nash tax charged by a country is monotonic in its relative size. When the hub is small and trade costs are relatively low $(\tau=0.2)$, the hub provides a subsidy to its firms while the spokes charge taxes; while the reverse is true when the spokes have relatively small shares of the population.

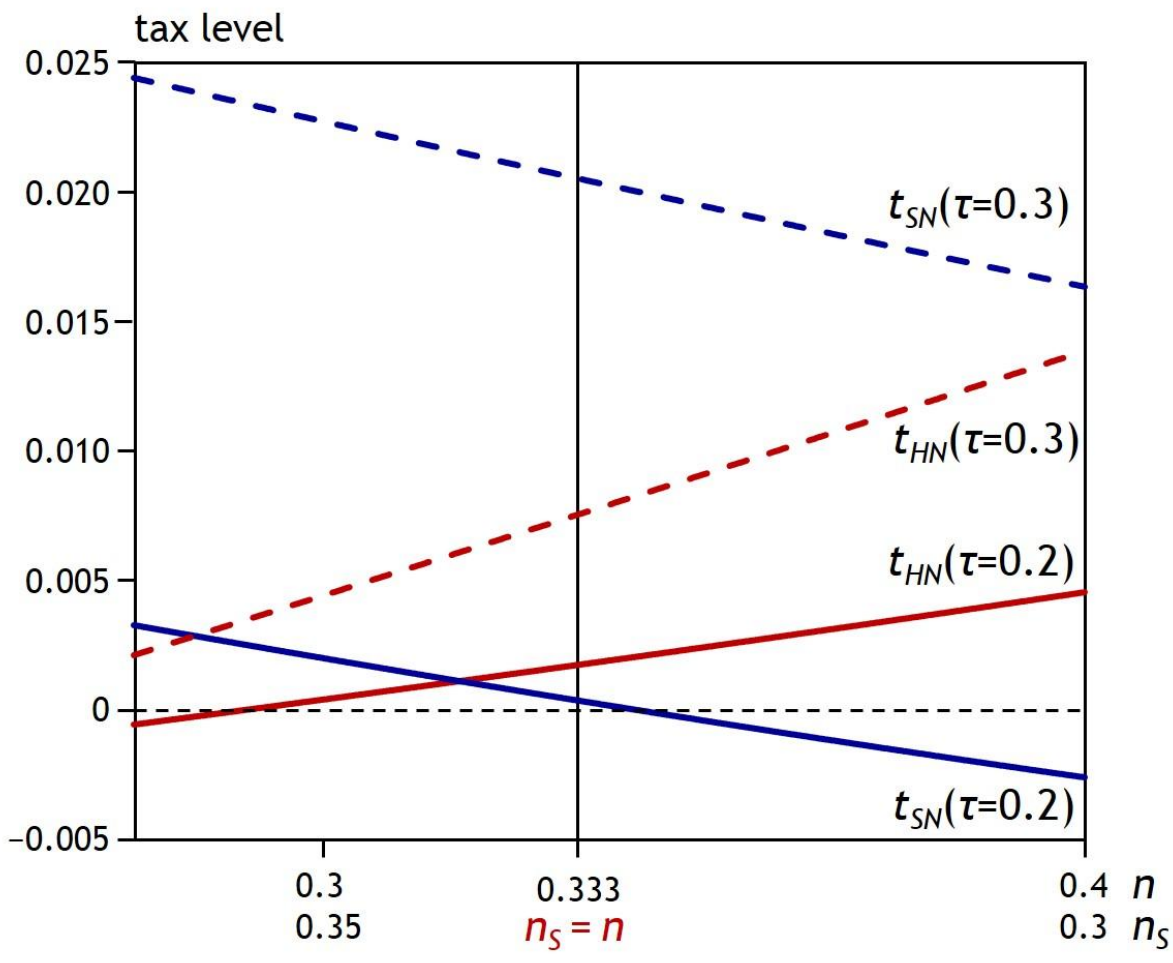

Figure 4. Nash taxes, trade costs and country size

Three additional aspects are worth noting. Firstly the race to the bottom is limited, as there is a range of the population allocation over which all countries impose taxes for both levels of trade cost. Secondly, in this example, the benefits of centrality depend upon the level of the trade cost, in that when the countries are equally sized and trade costs are low, the hub sets a higher tax than either spoke. However, increasing trade costs isolates national 
markets and reduces the benefits to a firm of a central location such that the hub compensates by offering the lower tax in equilibrium.

Finally, increasing the trade cost has a strong, positive impact on the levels of tax in both hub and spokes, but the effect is stronger for the spokes. Thus, we see in Figure 4 (for large $n$ ) that a higher trade cost can more-than-offset the impact of size and centrality such that the Nash equilibrium tax set by the spokes can exceed that of the hub. Thus efforts to reduce trade costs may intensify the race to the bottom in taxes and result in the spokes offering subsidies rather than imposing taxes and may lead, from (7), to further concentration of firms in the hub. Consequently, depending upon the impact on consumer surplus, transport infrastructure investments may have a negative impact on welfare in the region. ${ }^{18}$

While messy, the expressions in (15) seem to reflect the tension facing nations between generating revenue from high taxes on local firms and the desire to retain domestic industry in order to maximise consumer surplus. ${ }^{19}$ Figure 5 illustrates how taxes in the Nash equilibrium mitigate some of the effects of natural geography where we, again, consider two levels of trade costs $(\tau=0.2$ and $\tau=0.3)$. In each panel, the dashed lines indicate the number of firms per household captured by countries as a function of their populations in the absence of tax differences. We clearly see that, regardless of the level of trade cost, industry agglomerates in the hub as its population share increases. The solid lines show the location of industry when the countries set their Nash-equilibrium taxes. Even with the equilibrium taxes being used, the hub's centrality means that it still captures a disproportionate share of industry (as $\lambda_{H N}>\lambda_{S N}$ ). It is clear, however, that the distribution of firms across the region is less responsive to population changes when countries set their corporate taxes endogenously. Countries can impose taxes when their locations are attractive to firms and offer subsidies

\footnotetext{
18 Becker and Fuest (2010) consider the implications for tax competition and welfare of transport infrastructure investments in a 3-country model.

19 If the oligopolistic industry were to bring "better" jobs, this latter incentive to retain domestic firms would be reinforced.
} 
when they are geographically disadvantaged. As we saw in Figure 4, spokes will charge higher taxes than the hub when trade costs are high and this will reinforce the concentration of industry in the hub. In contrast, when trade costs are lower, which country (hub or spoke) offers the lower tax in equilibrium will depend upon the relative size of the hub and each spoke, such that a sufficiently large hub will charge a higher tax than the spokes (to the right of the dotted line in the left-hand panel).

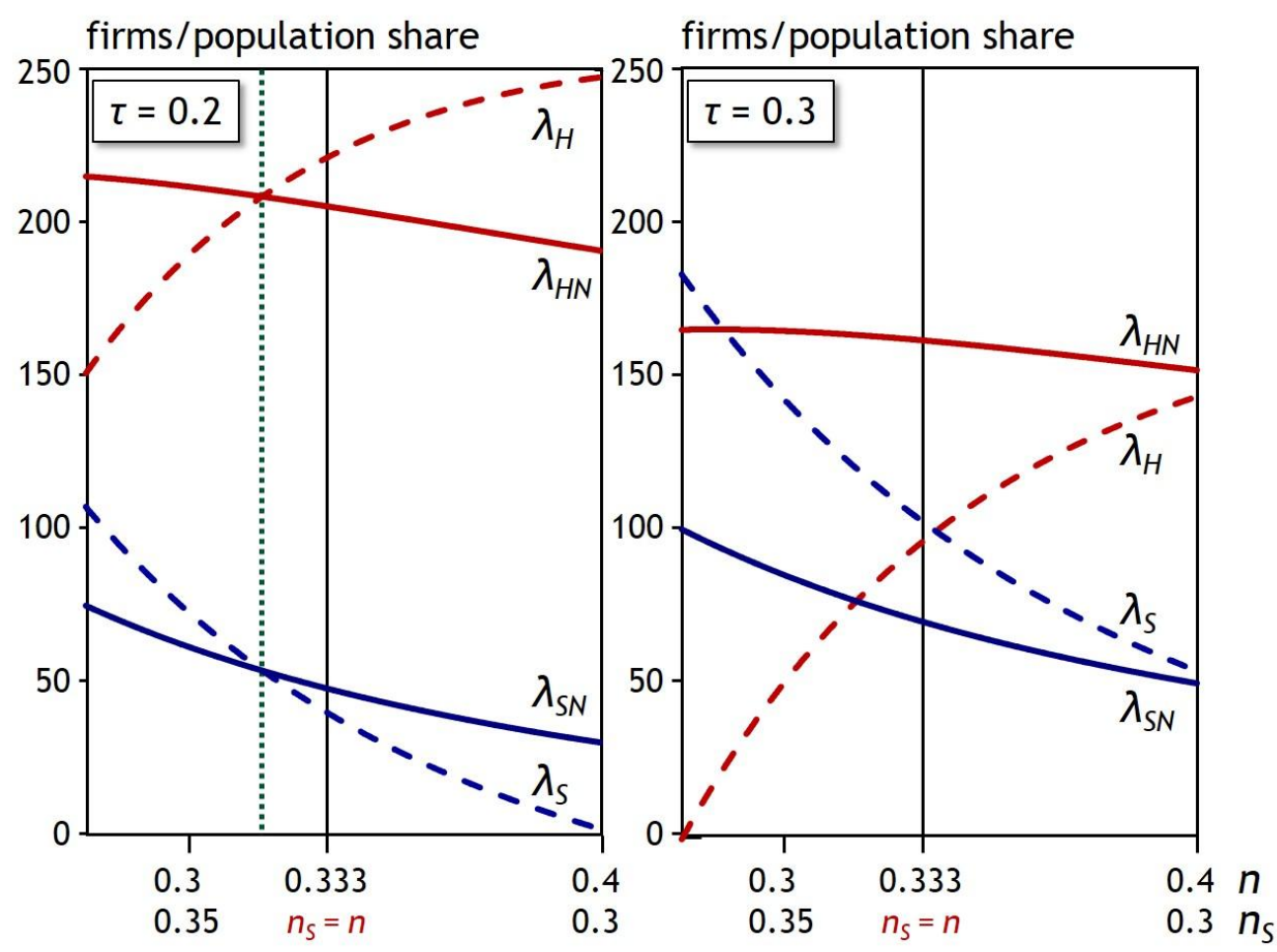

Figure 5. Nash taxes and location of industry

\section{The implications of centrality}

We have conducted our analysis of the location choices of firms, and the subsequent tax competition to influence these decisions, in a specific trading structure in which all international exchange must take place through a hub country. In our analysis thus far the hub has been distinguished from the spokes both in terms of its size and its pivotal role in trade. As this latter element is less well-understood, we now focus on the role that centrality has on our results. 
Consider a region that exhibits "triangular trade" amongst three countries, as illustrated in Figure 6. The three countries are the same size and export directly to each other without transhipment through another country. We shall contrast the outcomes of firm location and tax competition in this setting with our hub-and-spoke results. This will enable us to identify the implications of preventing direct trade between the spokes and could provide a justification for infrastructure investment that might enable this trade to take place. The hub-and-spoke model can differ from the triangular model, not only in the geography of international trade, but also in the size of the hub relative to the spokes. In order to focus on how geography influences location and equilibrium taxes, we set $n=1 / 3$ so that all countries are the same size in both the hub-and-spoke and triangular models. ${ }^{20}$

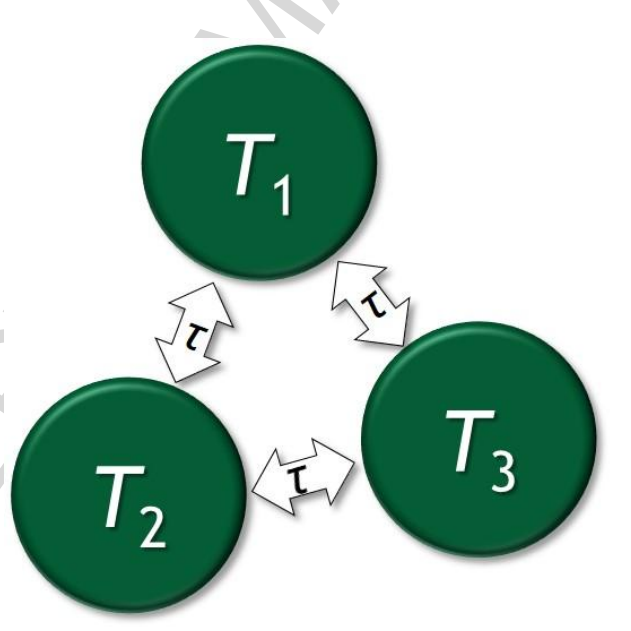

Figure 6. Triangular trade

The triangular model shares the same demand and production characteristics as the hub-and-spoke model. Thus consumers are characterised by equations (1) through (3). All production locations are identical, in that their cost of exporting to either foreign market is $\tau$. Given this symmetry and in the absence of any corporate taxes, the equilibrium allocation of the $k$ firms across the region is $k / 3$ in each country. Consequently, not only are firms' pre-tax profits the same across the region, prices and welfare of consumers will be identical in every country. Thus, we find that the equilibrium for triangular trade is characterised by:

\footnotetext{
${ }^{20}$ Thus this variant of the hub-and-spoke model corresponds to Figure 6 with one of the trading links severed.
} 


$$
X_{T}=\frac{(3 \mathrm{~A}-2 \tau) k}{9 \beta(k+1)}, \quad p_{T}=\frac{3(\alpha+\omega k)+2 \tau k}{3(k+1)},
$$

where the subscript $T$ refers to outcomes for the triangular model. ${ }^{21}$

We wish to contrast this with the corresponding equilibrium in the hub-and-spoke model, that is, when each country is endowed with one third of the region's population. Solving (5) and (6), using the equilibrium allocation of firms (7), yields the following:

$$
\begin{aligned}
X_{H}=\frac{2 \mathrm{~A}-3 \tau}{6 \beta}, & p_{H}=\frac{2 \omega+3 \tau}{2}, \\
X_{S}=\frac{(\mathrm{A}-\tau) k}{3 \beta(k+1)}, & p_{S}=\frac{\alpha+(\omega+\tau) k}{k+1} .
\end{aligned}
$$

We can also use (9) and (10) to determine welfare levels in the hub and spokes and, using (16), compare these to the welfare of citizens in the triangular region. Thus we have:

$$
\begin{gathered}
W_{H}=\frac{(2 \mathrm{~A}-3 \tau)^{2}}{24 \beta}+\frac{w}{3}, \quad W_{S}=\frac{[(\mathrm{A}-\tau) k]^{2}}{6 \beta(k+1)^{2}}+\frac{w}{3}, \\
W_{T}=\frac{[(3 \mathrm{~A}-2 \tau) k]^{2}}{54 \beta(k+1)^{2}}+\frac{w}{3},
\end{gathered}
$$

where the final term in each expression is the (fixed) share of wage income received in each country. The implications for national welfare resulting from the relative isolation of the spokes compared to both the hub and nations engaged in triangular trade are illustrated in Figure 7. We see that welfare in a spoke is always less than that in the hub and, indeed, less than that of countries in the triangular model. In contrast, the relative welfare of the populations in the hub and in triangular countries is ambiguous, as the schedules intersect each other.

\footnotetext{
${ }^{21}$ We do not develop this alternative model fully in this paper. We analyse a multi-country model of trade amongst heterogeneous nations in Darby, Ferrett and Wooton (2012). The triangular trade model is a simplified, special case of that structure.
} 


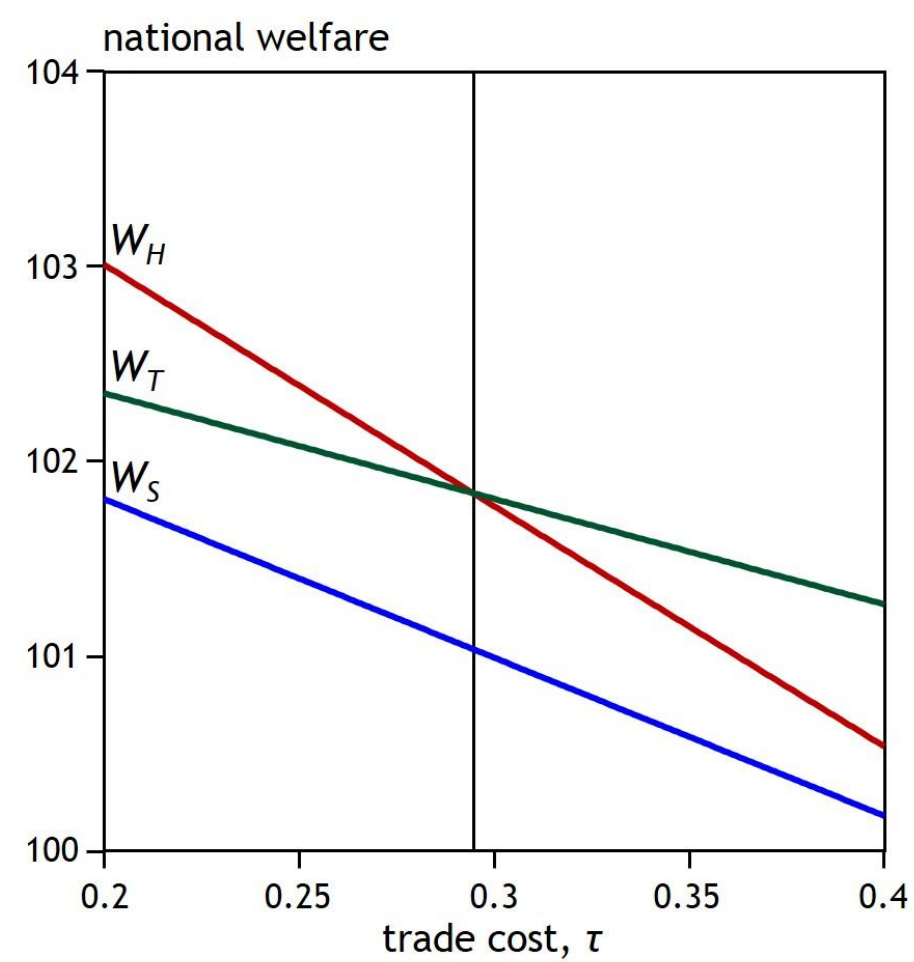

Figure 7. National welfare and trade costs

The comparison of outcomes turns on whether the hub receives more or less than an equal share of the firms in equilibrium. If we set $k_{H}{ }^{*}=k_{S} *$ in (7) we can solve for the critical trade cost $\tau^{*}=6 \mathrm{~A} /(3 k+209)$. This is the trade cost, illustrated earlier in Figure 3 by the vertical line, where all countries in the hub-and-spoke model endogenously attract the same number of firms as operate in each of the triangular countries. The welfare schedules of the hub and triangular countries coincide at the same trade cost in Figure 7. The explanation for this is straightforward. Each firm is able to segment its markets, setting its price in a national market dependent upon the costs of serving the market and the level of competition in the marketplace. When a hub has one third of the population and one third of the firms, it is effectively identical to a triangular country and consequently the market outcomes in terms of sales, price and welfare are the same. At lower trade costs, firms agglomerate in the hub, resulting in a more competitive environment than in a triangular country. In contrast, when the firms are evenly distributed across the region in the hub-and-spoke model, the local firms 
in the spokes face less competition from imports compared to those in the hub, resulting in lower welfare for residents of the spokes.

\subsection{Centrality and tax competition}

The differences between the trading structures is more apparent when corporate taxation is possible. Firms will be more "footloose" in the triangular model and respond more elastically to differences in national tax rates than in the hub-and-spoke model. This arises because no triangular country has a geographic advantage over any other, as they are identical in trading structure as well as in size. Despite their best efforts to use tax inducements to attract FDI, because the locations are identical to each other, the regional distribution of firms in the Nash equilibrium will be the same as occurs in the absence of taxes. Thus the only effect that international tax competition can have on welfare is its impact on the tax revenues that can be redistributed to households. Using (16) we find pre-tax profits of firms:

$$
\pi_{T}=\frac{(3 \mathrm{~A}-2 \tau)^{2}+2 \tau^{2}(k+1)^{2}}{9 \beta(k+1)^{2}},
$$

while the lump-sum tax that is levied in the Nash equilibrium is:

$$
t_{T N}=\frac{\tau k\lfloor 5 \tau-3(\mathrm{~A}-k \tau)\rfloor}{9 \beta(k+1)^{2}} .
$$

From Error! Reference source not found., we can see that the competing national governments will offer the firms a subsidy to invest when trade costs are below $3 \mathrm{~A}((3 k+5)$. At all relevant trade costs, the Nash tax is less than firm profits, which could be fully extracted from the firms if the three governments acted cooperatively in tax setting. Thus the triangular model strongly exhibits a race to the bottom in corporate taxes.

In contrast, the hub always has the benefit of centrality even when its population is the same as that of each of the spokes. This will have implications for the intensity of international tax competition and the degree to which a race to the bottom occurs. As we have 
seen, the outcome of the international tax competition in a hub-and-spoke framework results in different taxes being offered by the hub and the spokes, resulting in a redistribution of firms relative to the equilibrium in the absence of taxes. Thus the tax competition has two elements: the degree to which there is a race to the bottom in order to attract the FDI; and the resulting location of industry.

\section{The implications of tax-setting autonomy}

In our analysis, so far, we have assumed that the countries in the region are autonomous in their ability to set their corporate taxes. This competition between nations has the potential to induce an inefficient allocation of firms across the region, as well as resulting in lower tax revenues through a race-to-the-bottom in taxes.

Suppose that, instead, the region had a single tax-setting authority whose sole objective is to maximise the collective welfare of the three countries. In this situation, the problems of any race to the bottom would be eliminated. The tax authority could set taxes to maximise the revenues collected across the region and then these could be redistributed independently of where they were collected. Indeed, if the tax authority had to set a single tax for firms regardless of where they located in the region, the supranational agency's only decision would concern the level of this tax as, without differences in the taxes between the hub and spokes, there would be no ability on the part of the tax authority to influence the location of firms. ${ }^{22}$

If the regional authority were able to set country-specific corporate taxes, then it has two instruments that influence regional production activity and, consequently, the welfare of residents. The tax authority can choose the tax difference $(\Delta)$ between the hub and the spokes

\footnotetext{
${ }^{22}$ In essence, this is a case of the inability to rank second-best outcomes. If countries can set their own corporate taxes, they will do so in the light of their own particular circumstances but the international competition in taxes will drive down tax revenues. In contrast, this competition can be eliminated by having a tax-setter for the entire region but setting a single tax for all countries will not take into account the hub-and-spoke trading structure. We shall now consider a first-best solution that avoids these two pitfalls.
} 
to influence the locations of firms across the region, while tax levels $\left(t_{H}\right.$ and $t_{S}$ where $\left.t_{H}=t_{S}+\Delta\right)$ can be used to extract the maximum profits from the industry. Having a single authority setting the taxes ensures that there will be no race to the bottom arising from the tax competition amongst rival locations.

Regional welfare is found by summing (9) across the hub and two spokes,

$$
W \equiv S+T+w
$$

where consumer surplus is $S \equiv S_{H}+2 S_{S}$ and aggregate tax revenue is $T \equiv t_{H} k_{H}+2 t_{S} k_{S}$. From (10) and (13), we can find how aggregate welfare responds to changes in $\Delta$. Differentiating $W$ with respect to $\Delta$ and solving, yields the optimal regional tax difference $\Delta_{R}$ :

$$
\Delta_{R}=\frac{\tau(2 \mathrm{~A}-3 \tau)}{3 \beta(2 k+3)}>0,
$$

where the second derivative is negative indicating a maximum. Thus regional welfare is maximised when firms that locate in the hub face a higher tax than those in the spokes. This results in more firms operating in the spokes than would arise in the absence of corporate taxes or when a uniform tax is set by the regional authority. Thus aggregate welfare in a region can be increased by the imposition of difference taxes in each of the countries, where the hub's geographic advantage is offset by its firms being faced with a higher tax than those in the spokes. The welfare-maximising allocation of firms can be found by substituting (4) into (13):

$$
k_{S R}=\frac{3 \tau(k+1)^{2}-(k+2) \mathrm{A}}{2 \tau(2 k+3)}, \quad k_{H R}=k-2 k_{S R} .
$$


This result is illustrated in Figure 8, where aggregate welfare is plotted against the number of the firms in each spoke. It is clear that the regional authority also wants to have more production in the spokes than would arise in the Nash equilibrium $\left(k_{S N}\right){ }^{23}$

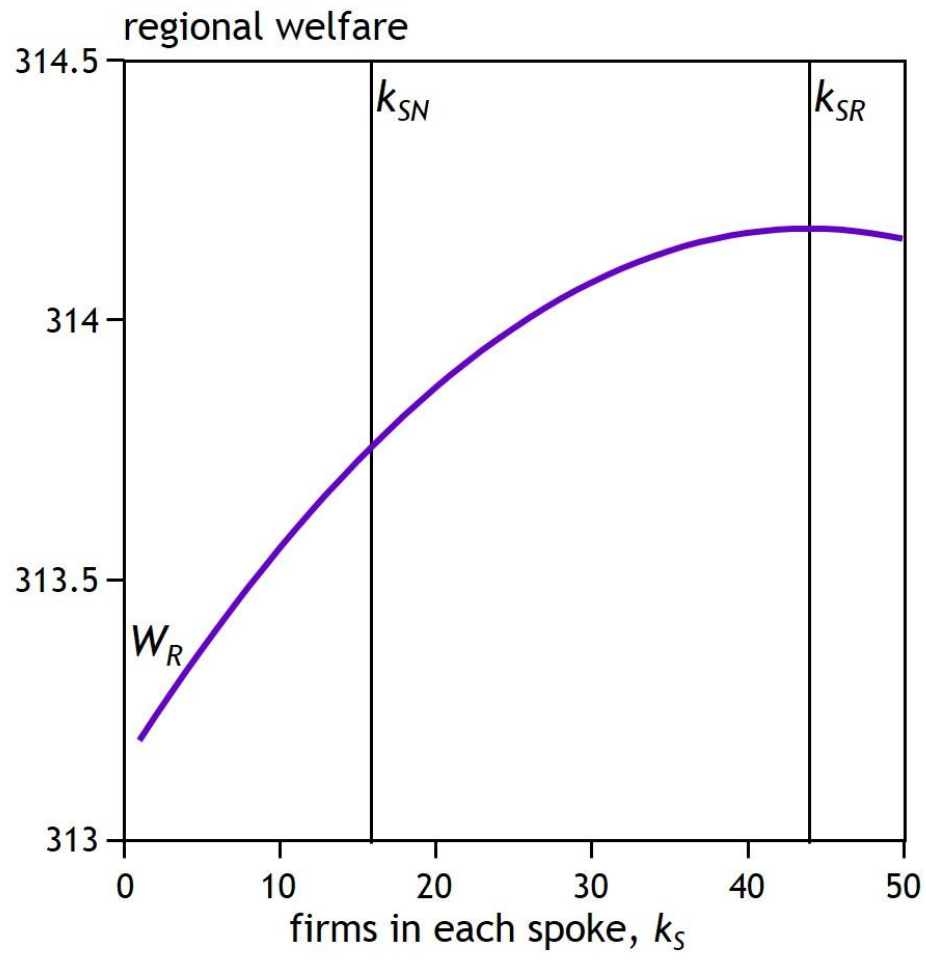

Figure 8. Regional welfare and the allocation of industry

A supranational, regional tax authority could divorce itself from the competition between countries, that results in similar taxes in the Nash equilibrium, and induce a redistribution of industry from the hub to the spokes. Having chosen the "best" allocation of industry through the difference in national taxes, the regional authority can then extract the firms' profits by choosing the levels of national taxes that fully extract industry profits.

Our results show that giving a supranational, regional tax authority the ability to set location-specific corporate taxes has important implications for the welfare of countries in the region. The optimal policy of encouraging more production in the spokes, relative to what would occur both in the absence of taxes and in the Nash equilibrium, means that households

\footnotetext{
23 The expressions in (5) show that prices in the spokes are higher than in the hub whenever the hub attract some firms. Thus, prices will only converge across the region when all industry is induced to move to the spokes.
} 
in the more-competitive hub will lose some of the advantage from its centrality as firms are induced to move out to the spokes.

\section{Conclusion}

In this paper we have set up a simple model of international tax competition for foreign direct investment. The novelty of our approach is in the geography of the supranational region where we have assumed that one of the countries is a hub through which all international trade must take place. We believe that this structure is applicable to trade amongst countries at the periphery of a large supranational region. Indeed, the implications of a UK government devolving tax-setting powers to Scotland, Wales and Northern Ireland provided the initial motivation for this paper.

In previous models of international tax competition for FDI, size was the only source of advantage in the game, resulting in larger countries setting higher corporate taxes. Now centrality also plays a role, giving firms in the hub easier access to foreign markets than enjoyed by firms located in the spokes. Depending on the relative sizes of the countries within the supranational region and the costs of trading between nations, size and centrality may work together or in opposition to each other to result in agglomeration of disproportionate shares of industry in either the hub or the spokes.

We determined the equilibrium outcomes of our hub-and-spoke trading structure with respect to the location of industry and the levels of corporate taxation. We have established that in this hub-and-spoke framework the race to the bottom is limited in that we can find equilibrium outcomes in which all countries impose taxes. Moreover, the central position of the hub is important in that, if countries are equally sized and trade costs are low, the hub will set a higher tax than either spoke. The trade cost has a strong positive impact on the levels of tax in both hub and spokes and efforts to reduce trade costs may result in lower taxes and 
more concentration of firms in the hub. Consequently, transport infrastructure investments may have a negative impact on the region overall.

In the hub-and-spoke framework, firms are less "footloose" than they would be in the equivalent trading system where all countries can trade directly with each other. In such a triangular model, firms respond more elastically to differences in national tax rates than in the hub-and-spoke model. This is because no triangular country has a geographic advantage comparable to that enjoyed by the hub. The Nash equilibrium in a triangular model with identical countries is characterised by a race to the bottom with identical taxes set by all nations and consequently the same distribution of firms as occurs in the absence of taxes.

Finally, we have considered how the outcome in the hub-and-spoke model would change if tax-setting powers were transferred from individual countries to a supranational, regional tax authority. The authority would be immune to the pressures of the race to the bottom resulting from international competition between hub and spokes. It could, however, create a difference in national taxes in order overcome firms' reluctance to produce in the more isolated spokes. While this policy would raise aggregate welfare, the citizens in the hub would be adversely affected from having fewer local producers.

These outcomes provide a justification for the calls for different corporate tax rates across a geographically diverse state, such as the UK, in order to offset the disadvantages faced by producers locating on the periphery of the economic area, as compared to those that chose a more metropolitan location. But rather than doing this at the cost of the intraregional rivalry that would arise if the tax setting powers were devolved, the superior outcome would be for the supranational tax authority to take into account the different circumstances facing central and peripheral countries within the region and set different taxes for each. 


\section{References}

Becker, Johannes, and Clemens Fuest (2010), "EU regional policy and tax competition." European Economic Review 54, 150-161.

Bjorvatn, Kjetil, and Carsten Eckel (2006), "Policy competition for foreign direct investment between asymmetric countries.” European Economic Review 50, 1891-1907.

Brander, James A., and Paul Krugman (1983), "A 'reciprocal dumping' Model of international trade.” Journal of International Economics 15, 313-323.

Darby, Julia, Ben Ferrett and Ian Wooton (2013), "FDI, trade costs and regional asymmetries.” CESifo Working Paper No. 4469 (November 2013).

Darby, Julia, Ben Ferrett and Ian Wooton (2012), "Intra-regional competition for FDI amongst heterogeneous nations." Mimeo.

Ferrett, Ben, and Ian Wooton (2010), "Competing for a duopoly: international trade and tax competition." Canadian Journal of Economics, 43, 776-794

Fumagalli, C., (2003), "On the welfare effects of competition for foreign direct investment." European Economic Review 47, 963-983.

Haaparanta, P., (1996), “Competition for foreign direct investment." Journal of Public Economics 63, 141-153.

Haufler, Andreas, and Ian Wooton (1999), "Country size and tax competition for foreign direct investment." Journal of Public Economics 71, 121-139.

Haufler, Andreas, and Ian Wooton (2006), "The effects of regional tax and subsidy coordination on foreign direct investment." European Economic Review 50, 285-305. 
Haufler, Andreas, and Ian Wooton (2010), "Competition for firms in an oligopolistic industry: the impact of economic integration.” Journal of International Economics 80, 239-248.

Olsen, T., and P. Osmundsen (2003), "Spillovers and international competition for investments." Journal of International Economics 59, 211-238.

Scottish Government (2009), "Freight in Scotland." Freight Statistics Project, http://www.scotland.gov.uk/Publications/2009/08/03104646/0.

Scottish Government (2011), "Corporation Tax: Discussion Paper Options for Reform." http://www.scotland.gov.uk/Publications/2011/08/corporation-tax-paper. 


\section{Highlights}

- We model tax competition for FDI between 3 countries in a hub-and-spoke pattern.

- A hub-and-spoke structure reflects trade in North America, Europe and the UK.

- The hub country enjoys centrality, while spoke-to-spoke trade must go via the hub.

- The key exogenous variables are country size and the hub-to-spoke trade costs.

- We show that spoke countries set low taxes to offset their disadvantageous locations. 